\title{
DE DEMIURGO A OPERÁRIO: UMA ANÁLISE GRAMSCIANA DO TRABALHO SOB O TAYLORISMO/ FORDISMO $^{1}$
}

\author{
From demiurge to labourer: a gramscian analysis of labour under \\ taylorism/Fordism
}

\section{De Demiurgo al operario: un análisis gramsciano del trabajo bajo el ta- ylorismo / fordismo}

Geraldo Augusto Pinto ${ }^{2}$

Universidade Estadual do Oeste do Paraná, Paraná, Brasil.

Recibido: 13 de enero de 2012. Aprobado: 30 de octubre de 2012.

\section{RESUMEN}

En el clásico estudio "Americanismo y fordismo", escrito en 1934, Antonio Gramsci analizó la influencia del taylorismo/fordismo sobre el desarrollo sociocultural de la sociedad estadounidense, especialmente los cambios operados en la cultura política de la clase obrera fabril. Relevando en el taylorismo/fordismo una amplia estrategia ideológica del capitalismo, Gramsci observaba en ese sistema más un simples conjunto de métodos para organizar y administrar actividades de trabajo. Trataba, especialmente, de un conjunto de principios que persuadía y coaccionaba a los trabajadores en sus acciones para, más allá del espacio de las empresas, situarlos dentro de un ideario y de un modo de vida perfectamente adecuados a las necesidades de la industrialización de masa emergente. En ese esfuerzo, Gramsci logró una significativa claridad acerca de la magnitud de la influencia de la estructura social, del

$1 \quad$ Este artículo se inscribe dentro do projeto: “O trabalho na América Latina e no Caribe”. Código: 28378/2009. Centro de Educação e Letras, Campus de Foz do Iguaçu, Universidade Estadual do Oeste do Paraná. Iniciado em 2009 e em andamento. El texto resulta do aperfeiçoamento de um trabalho apresentado e publicado no IV Seminário Científico Internacional "Teoria Política do Socialismo: Antonio Gramsci - a periferia e os subalternos”, FFC/UNESP, Marília, SP, Brasil, 15-18 ago. 2011.

Su revisión en portugués fue realizada por la Dra. Menara Lube, a quienes los editores de Si Somos Americanos le expresan sus agradecimientos.

2 Bacharel em Sociologia e Ciência Política, Mestre e Doutor em Sociologia. Professor Adjunto da Universidade Estadual do Oeste do Paraná - Programa de Pós-Graduação em Sociedade, Cultura e Fronteiras, Coordenador do Grupo de Pesquisa em Estado, Sociedade, Trabalho e Educação. Correo electrónico: geraldoaugusto@hotmail.com 
Estado y de la lucha de clases sobre el desarrollo de las fuerzas productivas, principalmente en lo que toca a la gestión del trabajo, demostrando el carácter dialéctico entre esas esferas. Nuestro objetivo, en este artículo, será recoger puntos de esa lectura gramsciana del taylorismo/fordismo, observando el alcance y la profundidad de sus argumentos.

PALABRAS CLAVE: Fordismo, Antonio Gramsci, Estado de bienestar.

\begin{abstract}
In his classic study "Americanism and Fordism", written in 1934, Antonio Gramsci dedicated himself to analyzing the influence of Taylorism/Fordism on American society's social and cultural development, especially transformations operated in the political culture of the factory labourer. Revealing in Taylorism/Fordism capitalism's ample ideological strategy, Gramsci perceived in this system more than a simple set of methods of organizing and managing labour activities. It was, above all, a set of principles that persuaded and coerced labourers in their actions beyond the companies' space, conforming them within ideas and a lifestyle perfectly adequate to the necessities of the emerging mass industrialization. In this effort, Gramsci attained significant clarity regarding the magnitude of the influence of the social structure, of the State and of the class struggle over the development of the productive forces, mainly in regards to the management of labour, demonstrating the dialectic character of these spheres. Our goal in this work, is to resume points of this Gramscian reading of Taylorism/Fordism, observing the scope and depth of his arguments.
\end{abstract}

KEYWORDS: Fordism, Antonio Gramsci, Welfare State.

\title{
I. INTRODUÇÃO
}

No início do século XX, a intensa concentração e centralização do capital industrial nas potências capitalistas centrais refletem os movimentos de uma crescente internacionalização dos mercados e o acirramento da concorrência capitalista no plano mundial. Em tal contexto, emergem diversas experiências de exploração do trabalho assalariado, entre as quais, o sistema de gestão da força de trabalho desenvolvido por Frederick W. Taylor (1856-1915) e sua assimilação por Henry Ford (1862-1947) no desenvolvimento da produção industrial de massa e em linha seriada. 
O deslanchar do fordismo-ou taylorismo/fordismo, como o denominaremos neste artigo- ao longo do século XX, viria a assumir, contudo, dimensões que ultrapassaram o seu papel de mero sistema de gestão do trabalho e racionalização de processos produtivos. Acompanhado de uma série de ações no âmbito da sociedade civil e do Estado, o taylorismo/fordismo configurou-se como um movimento de reestruturação do capital cujo epicentro foi um país que, em meados do século XX, desbancou a liderança britânica, tornando-se o núcleo central da expansão do capitalismo no plano internacional: os Estados Unidos da América (EUA).

O taylorismo/fordismo, mais do que um sistema de gestão, embasou um reposicionamento dos proprietários dos meios de produção contra o poder da classe trabalhadora, desqualificando o saber-fazer tácito do operariado e solapando o antigo sindicalismo de ofício - o qual sofreria nos EUA a absurda acusação de apropriar-se do conhecimento técnico em proveito próprio (ou seja, em proveito dos trabalhadores que os acumularam ao longo da história). Por fim, difundido junto ao advento do Estado de Bem-Estar Social, o taylorismo/fordismo empreendeu um projeto de sociabilidade cujo objetivo era compor um coletivo de homens e mulheres dispostos não só a trabalhar, no âmbito das empresas, mas a viver, em todos os demais espaços do cotidiano, uma vida maquinal, enquanto consumidores de serviços e produtos industrializados em massa.

No presente artigo, tomaremos por foco esses pontos, buscando tratá-los dentro da análise crítica desenvolvida por Antonio Gramsci (1891-1937) em seu clássico "Americanismo e fordismo". Escrito em 1934, esse texto de Gramsci analisou com grande lucidez o taylorismo/fordismo, desvendando, por trás de sua aparência fenomênica enquanto simples conjunto de métodos de organização do trabalho, sua essência enquanto projeto societal, elaborado pela intelectualidade orgânica da burguesia industrial como um conjunto de princípios que deveriam persuadir e coagir os trabalhadores pela introjeção de um ideário e de um modo de vida adequados às necessidades da industrialização de massa emergente.

Nosso objetivo será expor e discutir pontos dessa análise de Gramsci, com o intuito de demonstrar sua vigorosa crítica e sua atualidade. Afinal, compreender e explicar o funcionamento do modo de produção capitalista, especialmente em períodos de crise como o que se manifesta no atual momento, é uma tarefa que se nos impõe de forma incontornável. E que requer, sem dúvida, um predicado imprescindível na análise histórico-materialista: a perspectiva de totalidade, ou seja, uma análise que resgate e articule as relações entre, de um lado, $\mathrm{o}$ ataque aos direitos e às formas de mobilização da classe trabalhadora; e, de outro, a manipulação do Estado e dos organismos sindicais 
mediante alianças e formas de consentimento, pelas quais o capital divide socialmente seus riscos e prejuízos, dispersando, ao mesmo tempo, suas oposições.

\section{TAYLOR E FORD}

Comecemos pelo fato de que, sem os experimentos de Frederick Taylor, Henry Ford dificilmente teria chegado à concepção de sua produção seriada de massa. Apesar de não citá-lo como um predecessor, é curioso como em sua popular autobiografia Minha vida e minha obra, Henry Ford concebe, tal como Taylor, o aviltamento do trabalho humano como decorrência da própria "natureza" dos homens e não como uma decorrência da divisão técnica e social imposta pelo modo de produção capitalista:

Necessariamente o trabalho de muitos homens tem de ser pura repetição de movimentos, pois de outro modo não se pode conseguir sem fadiga a rapidez da manufatura que faz descer os preços e possibilita os altos salários. Algumas das nossas operações são excessivamente monótonas, mas também são monótonos muitos cérebros; inúmeros homens querem ganhar a vida sem ter que pensar - e para estes a tarefa unicamente de músculo é a boa. Possuímos em abundância tarefas que exigem cérebro ativo, e os homens que no trabalho de repetição se revelam de mentalidade ativa não permanecem nele muito tempo (Ford 1995:148-49).

De fato, as experiências de Henry Ford somente puderam ser realizadas sobre a plataforma da divisão técnica das funções e tarefas dos processos de trabalho entre numerosos agentes, conforme fora desenvolvido pelo sistema de Taylor. Pois, organizar uma produção em larga escala requer atingir-se um limiar mínimo de padronização dos produtos, o que, por sua vez, também exige uma padronização dos próprios processos produtivos envolvidos.

Por outro lado, se a divisão técnica do trabalho sob o taylorismo já havia permitido que se distribuíssem os trabalhadores e suas ferramentas ao longo de uma linha (tão baixo era o grau de complexidade da intervenção de cada indivíduo no processo total imposto por esse sistema), ao dividir o trabalho em gestos repetitivos e os distribuir em postos fixos, o taylorismo também já havia tornado desnecessária a busca por trabalhadores qualificados e até mesmo a necessidade de treinamentos mais longos. Ou seja, o sistema de Taylor permitiu aumentar a rotatividade dos operários sem que isso, dentro de certos limites, viesse a afetar a continuidade da produção. Taylor, portanto, engendrara uma divisão do trabalho não apenas técnica, mas também so- 
cial. Sem contar a significativa intensificação do volume e dos ritmos, elevados de forma brutal mediante o estudo e o controle dos tempos e movimentos dos trabalhadores em cada posto (Taylor 1970; Silva 1974; Braverman 1987; Fleury e Vargas 1983).

Portanto, se é certo que a linha de série fordista consolidou a imposição, aos sujeitos do trabalho, de um ritmo e de um volume uniformes de suas tarefas, ditados pela velocidade maquinal dos objetos de trabalho sob a condução das gerências, o saber-fazer inerente a tais tarefas, por seu turno, necessariamente também já se encontrava uniformizado pelo "the one best way" de Taylor. Uma multidão de trabalhadores especializados, por fim, teve seus salários rebaixados ou perdeu o emprego, ampliando o exército industrial de reserva.

O taylorismo/fordismo, desse modo, conjugando dois sistemas de organização e gestão da força de trabalho, intensificou a exploração da classe trabalhadora pelo capital, elevando a produtividade do trabalho e, por conseguinte, a massa de mais-valia, num processo que se iniciou especialmente no período entre as décadas de 1880-1890 e a Primeira Grande Guerra (1914-1918) e que caracterizou uma potencialização das forças produtivas capitalistas herdadas da Segunda Revolução Industrial, sob uma estrutura de concentração maior do capital industrial-financeiro (Souza 1992).

\section{A “GRANDE FAMÍLIA INDUSTRIAL”}

Ao dispor em uma linha seriada as várias atividades de transformação do objeto de trabalho e reduzir, com isso, a atuação dos trabalhadores a tarefas repetitivas e com um grau mínimo de intervenção, Henry Ford os tornou facilmente substituíveis pelas empresas. Obteve, contudo, uma imediata resposta combativa dos sindicatos de trabalhadores, que se alarmaram com a destruição das suas qualificações e com a iminente possibilidade de rebaixamento do valor dos seus salários. Insatisfeito com os altos índices de rotatividade e absenteísmo e confiante de que seu plano se reverteria num aumento substancial da capacidade produtiva e dos lucros da empresa em médio prazo, Henry Ford reagiu com a demissão dos trabalhadores combativos, anunciando no dia seguinte (05 de janeiro de 1914) um salário de $\$ 5$ dólares por uma jornada de 8 horas (cerca do dobro do que a maioria na fábrica ganhava até então).

Para receber tal salário, contudo, não bastava aos trabalhadores apenas submeterem-se à linha de série. Os candidatos deveriam comprovar que seguiam um estilo de vida que aprouvesse a Henry Ford e, para isso, instituiu-se, na Ford Motor Company, um departamento especializado a examinar e a intervir periodicamente na vida privada 
dos seus assalariados, por meio de um corpo de assistentes sociais que regularmente lhes visitavam para averiguar seus comportamentos e lhes inculcar valores como a fidelidade conjugal, a estabilidade familiar e emocional, a repulsa ao álcool e à vida boêmia, o apego à religião e ao patriotismo (Souza 1992).

A Ford Motor Company agia, assim, diretamente nas conexões entre a vida particular dos seus assalariados e o desempenho, ou produtividade, que estes atingiam no espaço da empresa, afinal, como bem aponta Dias (1999:105), a "estabilidade operária (familiar, sexual, etc.) passa a ser condição essencial de eficácia no trabalho", assim como "o 'desregramento' sexual, o alcoolismo e, diríamos hoje, as drogas interessam fundamentalmente como condição de racionalização da produção e não apenas do ponto de vista moral". Nas palavras de Gramsci:

Deve-se destacar o relevo com que os industriais (especialmente Ford) se interessaram pelas relações sexuais dos seus dependentes e pela acomodação de suas famílias; a aparência de "puritanismo" assumida por este interesse (como no caso do proibicionismo) não deve levar a avaliações erradas; a verdade é que não é possível desenvolver o novo tipo de homem solicitado pela racionalização da produção e do trabalho, enquanto o instinto sexual não for absolutamente regulamentado, não for também ele racionalizado (1991:392).

Complementarmente às inspeções no ambiente familiar, eram comuns outras formas de persuasão buscando obter um máximo de auto-disciplinamento e auto-exploração dos trabalhadores, como os "concursos do operário-padrão, e a emulação ao trabalhador Ford como o responsável pela construção de uma nova sociedade..." (Souza 1992:22). Tal estrutura de controle ideológico refletia nada menos que um conjunto de condições desumanas impostas aos trabalhadores pelo sistema taylorista/fordista, entre cujas consequências-das quais a Ford Motor Company e outras empresas buscavam a todo custo se esquivar - estava o surgimento de hábitos compulsivos, como o alcoolismo, além dos acidentes e das lesões osteomusculares por esforços repetitivos (adoecimento crônico hoje comumente reconhecido em muitos ambientes de trabalho). Retomando os apontamentos de Gramsci:

É preciso estudar as iniciativas "puritanas" dos industriais americanos tipo Ford. É claro que eles não se preocupam com a "humanidade" e a "espiritualidade" do trabalhador, que são imediatamente esmagadas. Esta "humanidade e espiritualidade" só podem existir no mundo da produção e do trabalho, na "criação" produtiva; elas eram absolutas no artesão, no "demiurgo", quando a personalidade do trabalhador refletia- 
se no objeto criado, quando era ainda bastante forte o laço entre arte e trabalho. Mas é exatamente contra este "humanismo" que luta o novo industrialismo (1991:398).

Gramsci aponta aqui, de maneira lúcida, a importância do trabalho enquanto base da sociabilidade, evocando a figura do "demiurgo". Este termo aparece em cadernos anteriores ao Quaderno $22(\mathrm{~V})$, que foi redigido em 1934 e contém o escrito "Americanismo e fordismo". Por exemplo, no Quaderno 8 (XXVIII), redigido entre 1931-1932, há a seguinte anotação: "\$(150). Nozioni enciclopediche. Demiurgo. Dal significato originario di 'lavorante per il popolo, per la comunità' (artigiano) fino ai significati attuali di 'creatore' ecc. (cfr scritti di Filippo Burzio)" (Gramsci s. d.:1.032).

Tudo aponta que Gramsci ateve-se, no que denomina como uma noção enciclopédica, a um significado etimológico específico do termo, muito próximo do que Sennett (2009) também identificou recentemente (embora sem se referir ao estudo de Gramsci) como a palavra grega demioergos, oriunda da conjugação de demios (público) e ergon (produtivo) e que se refere aos artífices da Grécia arcaica. Importa notar que os artífices, ou demioergoi, representavam em tal sociedade a gênese do processo civilizatório de que os gregos antigos muito se orgulhavam. Um processo em que, mediante a associação entre trabalho manual e intelectual, não só novas ferramentas foram criadas pelo homem, mas, sobretudo, a sua adequada aplicação, guiada pelo bem coletivo, é que passou a adquirir crescente foco de atenção. As habilidades e capacitações daí advindas alçaram, assim, o status de um aprendizado socialmente necessário a fim de proporcionar a cada geração um meio de coesão cultural.

Abalizando-se nessa concepção histórica do "demiurgo", Gramsci recupera a figura do trabalhador que age sobre o mundo à sua volta e o transforma de modo consciente, refletindo-se e, ao mesmo tempo, aperfeiçoando-se enquanto ser social na sua própria criação, tal qual um artesão em seus experimentos, trazendo à tona, com isso, um elemento central do materialismo histórico marxiano: o fato de que na luta pela sobrevivência, ao transformar a natureza, os homens também se transformam, adquirindo sempre novos conhecimentos e habilidades; ou seja, ao construir o mundo objetivo, o ser humano também se constrói como sujeito. Situação esta expressa com grande precisão por Marx e Engels (2009:87) nas seguintes palavras:

Pode-se distinguir os homens dos animais pela consciência, pela religião ou pelo que se queira. Mas eles mesmos começam a se distinguir dos animais tão logo começam a produzir seus meios de vida, passo que é condicionado por sua organização corporal. Ao produzir seus meios de vida, os homens produzem, indiretamente, sua própria vida material. 
Por não apenas adaptar-se à natureza ao seu redor, transformando-a, mas, sobretudo, por reflexionar acerca desta sua condição de existência material e do papel que desempenha na produção da própria vida, o ser humano, como um "demiurgo" de seu destino, passa a organizar as suas próprias relações sociais e a articulação destas com a natureza de um modo crescentemente diversificado e, sobretudo, "humanizado". Marx, aliás, foi especialmente enfático a respeito desse processo, ao qualificar o trabalho humano como algo sui generis, portanto, distinto da transformação do mundo objetivo realizado pelos demais seres:

Pressupomos o trabalho numa forma em que pertence exclusivamente ao homem. Uma aranha executa operações semelhantes às do tecelão, e a abelha envergonha mais de um arquiteto humano com a construção dos favos de suas colméias. Mas o que distingue, de antemão, o pior arquiteto da melhor abelha é que ele construiu o favo em sua cabeça, antes de construí-lo em cera. No fim do processo de trabalho obtém-se um resultado que já no início deste existiu na imaginação do trabalhador, e portanto idealmente. Ele não apenas efetua uma transformação da forma da matéria natural; realiza, ao mesmo tempo, na matéria natural seu objetivo, que ele sabe que determina, como lei, a espécie e o modo de sua atividade e ao qual tem de subordinar sua vontade. E essa subordinação não é um ato isolado. Além do esforço dos órgãos que trabalham, é exigida a vontade orientada a um fim, que se manifesta como atenção durante todo o tempo de trabalho, e isso tanto mais quanto menos esse trabalho, pelo próprio conteúdo e pela espécie e modo de sua execução, atrai o trabalhador, portanto, quanto menos ele o aproveita, como jogo de suas próprias forças físicas e espirituais (Marx 1996:297).

Para além da tese de que o ser humano se humaniza pelo trabalho, num processo de experimentação mediante o qual se percebe como sujeito de suas ações, é interessante notar, ademais, como Marx, nessa passagem de sua obra de maturidade, lançou luz precisamente ao "processo de trabalho", ao esclarecer que, no transcurso de todo trabalho, há um sucessivo estabelecimento prévio de finalidades, requerendo do ser humano a obrigação de se orientar decisivamente e agir de modo específico e causal em cada momento para garantir que tais finalidades ocorram como continuidade de suas concepções mentais. O objetivo de Marx, nesta formulação, certamente foi deixar claro que, retirando-se do sujeito a concepção e a finalidade do seu trabalho e lhe impondo, de forma unilateral, operações mentais e corporais marcadas por tempos e movimentos alheios à sua vontade, promove-se não apenas um esmagamento brutal de sua corporeidade, como, sobretudo, uma alienação na esfera de sua subjetividade, por meio de uma inversão ontológica que o destitui como sujeito de sua criação, desumanizando-o, por conseguinte. 
Se há, portanto, uma clara necessidade do capital em transformar o trabalho humano em mercadoria e, como parte deste transcurso, engendrar sistemas eficientes de organizar e gerir o consumo daquela que é a rainha entre todas as mercadorias-a força de trabalho, cujo predicado é o de gerar valor-, há, no entanto, paralelamente, uma necessidade vital de se conceberem determinadas formas de sociabilidade cujo fim é gerar um conjunto de hábitos e comportamentos que sejam complementares às necessidades da acumulação capitalista, amparando, assim, a racionalização do trabalho assalariado. Leitor profundo de Marx e observador atento das transformações dos processos de trabalho postas em curso pelo taylorismo/fordismo, Gramsci (1991:398) assinalou, acertadamente:

As iniciativas "puritanas" só têm o objetivo de conservar, fora do trabalho, um determinado equilíbrio psicofísico que impeça o colapso fisiológico do trabalhador, premido pelo novo método de produção. Este equilíbrio só pode ser externo e mecânico, mas poderá tornar-se interno se for proposto pelo próprio trabalhador, e não imposto de fora; se for proposto por uma nova forma de sociedade, com meios apropriados e originais.

A abstinência e aversão a extravagâncias por parte de seus assalariados, pregada por Henry Ford como complemento à relação conjugal estável, jamais implicou, portanto, uma valorização da estrutura familiar em si mesma, mas, antes, uma submissão desta às necessidades da reprodução da força de trabalho, como bem aponta, em sua análise do texto de Gramsci, Dias (1999:100), alertando, inclusive, para a atualidade dessas questões:

A família deixou de ser o elemento socializador básico, função que passa à fábrica. As formas familiares, os tempos e os gestos, a sexualidade, a convivência disciplinada, tudo isso passou a ter uma grande automaticidade. Algumas das idéias caras ao neoliberalismo têm aqui sua origem: entre outras a possibilidade do sindicato de empresa acoplado com a prática da Família Ford. Assim Trabalho e Vida Pessoal se imbricam fortemente na permanente tentativa de engolfar o conjunto da personalidade do trabalhador. A subordinação é, agora, quase total. Introduz-se, neste processo, tanto a coerção brutal quanto o prêmio (o "five dollars day").

Ao promover a interiorização de novos valores no coletivo de trabalhadores, visando estabelecer, para além da fábrica, uma sociabilidade voltada aos objetivos da produção de massa, o assalariamento assumiria um papel fundamental. Afinal, se o assalariamento é, por excelência, a forma social que mascara a troca desigual entre capital e trabalho, sendo a própria consolidação do comércio de trabalho humano (tornado mercadoria, força de trabalho), com o deslanchar da industrialização de massa, a satisfação de praticamente toda necessidade humana, desde a mais básica, é submetida às regras da 
acumulação de capital mediante a consolidação de um mercado de consumo de massa controlado por corporações cada vez maiores e centralizadoras.

Os altos salários e o controle ideológico, tais como postos em prática por Henry Ford em sua empresa, cumpriram, assim, a um só tempo, o papel de disciplinar e desmobilizar os trabalhadores. Primeiramente, por provocarem um elastecimento dos patamares de desempenho individual e coletivo no trabalho, mediante o efeito em cadeia gerado pelos assalariados que se dispuseram e, de fato, foram capazes de superar a produtividade média dos demais companheiros à época. Em segundo lugar, porque se estabeleceu também, gradualmente, um nexo entre a produção de massa e a reprodução da força de trabalho. Submeteu-se, enfim, a classe trabalhadora a um circuito fechado dado pela combinação entre o aumento da taxa de mais-valia relativa e o rebaixamento dos custos de reprodução da força de trabalho (Souza 1992:28). Assim:

[...] [Tanto] pela urbanização bem como pela difusão da produção em massa de bens duráveis e não duráveis, destinados ao consumo popular, o bloco industrial buscava "integrar" e "limitar" a reprodução operária ao campo do valor-mercadoria, reduzindo em muito a exterioridade da reprodução operária frente à produção capitalista. [...] Lograva-se, pela via desta articulação, a possibilidade de subordinar, ainda que parcialmente, a determinação do valor de reprodução da força de trabalho, à lógica governante do valor-mercadoria, extraindo-a, desta maneira, do campo ideológico em que se desenvolvia a luta de classes.

Portanto, mais do que uma faceta complementar da urbanização, a reprodução da força de trabalho pela via salarial foi desde sempre um importante instrumento de persuasão política da classe trabalhadora pelas elites, enquanto buscam legitimar sua dominação no seio de uma sociedade em construção. A reprodução salarial foi o mecanismo basal da dominação da burguesia sobre o conjunto heterogêneo de camadas sociais que constituíam uma sociedade ainda em transição, na medida em que vinculava, reduzia e limitava a compreensão acerca das condições de vida e de trabalho ao campo de possibilidades impostas pela acumulação capitalista, obstaculizando o debate sobre a historicidade desse sistema social. Não por acaso, portanto, a urbanização, a industrialização e o assalariamento formaram o tripé da reprodução da sociabilidade capitalista, complementarmente à funcionalização da família nessa estrutura social. Diz-nos Souza (1992:31), a respeito:

O novo padrão de reprodução possibilitou o reordenamento do grupo familiar, em torno das atividades de consumo, de repouso e de reprodução biológica, fixando-ocomo "célula básica de consumo"- em torno de um conjunto de serviços e equipamentos coletivos, sobre os quais se ergueria a hegemonia do grupo dirigente. Todas as 
antigas funções produtivas e reprodutivas da unidade doméstica-isto é, da produção artesanal à procriação - podiam ser, definitivamente, extirpadas de seu ambiente natural— a família, antiga unidade de trabalho e de reprodução.

Em suma, estabeleceu-se uma sociabilidade que não provinha mais das trajetórias tradicionais de formação social e cultural. A família assumia, nesse sentido, um papel periférico na sociedade, apenas como elemento de reprodução das relações sociais regularmente impostas pela mecanização da produção e do consumo de massa sobre o indivíduo anônimo, homogêneo e dispensável que nasce de seu ventre. Prossegue Souza (1992:32):

$\mathrm{O}$ ambiente com o qual se buscava romper era aquele definido pelos limites naturais da antiga família, baseada em seus laços amplos de consangüinidade e de solidariedade, bem como aquele contido pelas tradições de ofício [...]. No lugar, portanto, da consangüinidade e da solidariedade entre membros do mesmo ofício, a empresa se erigia como o espaço de concreção da "grande família industrial".

A hegemonia passa a ser construída a partir dos espaços constituídos pelo trabalho assalariado e pelo mercado de consumo. O taylorismo/fordismo e a industrialização de massa, portanto, terminaram por realizar, de fato, "afirmação do Manifesto do Partido Comunista: o capitalismo acaba com a família como elemento socializador fundamental. O mundo fabril e seus aparelhos passam a centralizar essa socialização” (Dias 1999:107).

\section{A “LIBERDADE INDUSTRIAL" E O “BEM ESTAR SOCIAL"}

Nesse complexo de forças estavam os sindicatos de operários, como um entrave fundamental ao avanço de tais mudanças, elo de manutenção da unidade operária e espaço de posicionamento público de suas reivindicações. A construção de uma nova sociedade, racionalizada e disciplinada pela fábrica taylorista/fordista - numa palavra, o "americanismo", como o chamara Gramsci-, teve de enfrentarnos EUA o antigo sindicalismo de ofício, modelo que vigorou na Europa no século XVIII e cuja luta consistia principalmente na defesa dos ofícios e qualificações pelos trabalhadores. Escreveu Gramsci (1991:382):

A luta que se desenvolve na América... é ainda pela propriedade do ofício, contra a "liberdade industrial", isto é, semelhante à luta que se desenvolveu na Europa no século XVIII, se bem que em outras condições; o sindicato operário é mais a expressão corporativa da propriedade dos ofícios qualificados do que outra coisa. Assim, o seu destroncamento, exigido pelos industriais, tem um aspecto "progressista". A ausência 
da fase histórica européia que, inclusive, no campo econômico é assinalada pela Revolução Francesa, deixou as massas populares americanas no estado primitivo, devendose acrescentar a isto a ausência de homogeneidade nacional, a mistura das culturasraças, a questão dos negros.

Ao classificar como "primitivo" o estado das artes da organização política do operariado estadunidense das primeiras décadas do século XX e ver, ademais, na destruição do sindicalismo de ofício um aspecto "progressista”, Gramsci não estava desconsiderando a importância da luta operária pela salvaguarda do saber-fazer acumulado historicamente pela classe trabalhadora. Sua intenção, tomando por base o estado das lutas sindicais européias do mesmo período, foi chamar a atenção para a necessidade de construção de uma resistência operária nos EUA como um projeto mais amplo de luta classista contra o capital, em um momento em que este entrava em uma fase de intensa concentração e centralização nas potências capitalistas centrais, a começar pelos EUA, território onde germinavam, por excelência, novos desdobramentos e morfologias nos meios de produção.

No mesmo sentido, ao patronato estadunidense e ao conjunto da burguesia industrial monopólica, a destruição dos sindicatos de ofício não representava mais do que a "ponta de lança" de um projeto maior e mais duradouro. Vislumbrava-se liquidar os espaços de avanço de ideologias e mobilizações operárias radicais, usando da força ou da assimilação dos trabalhadores nas malhas da sociedade do consumo de massa. Fragilizada em suas bases, a classe trabalhadora passaria a sofrer sucessivos ataques, como o assalto aos direitos trabalhistas baseados nos ofícios e nas qualificações tradicionais. Em meio a esta luta contra a liquidação pelo taylorismo/fordismo dos saberes-fazeres tácitos da classe trabalhadora, o sindicalismo combativo estadunidense viria a ser acusado pelo patronato, no início do século XX, de opor-se à "liberdade industrial", isto é, de apropriarse de um patrimônio de conhecimentos e de impedir que as empresas empregassem seus próprios métodos para a organização dos ofícios industriais (Dias 1999).

Ora, a destruição desse sindicalismo era uma necessidade ao capital e foi, de fato, levada a cabo na edificação da sociedade fordista. O Estado, contudo, assumiu importante papel nesse processo. Lembremos que, após a quebra da Bolsa de Nova Iorque em 1929 e da imensa crise econômica gerada em âmbito internacional, as relações entre as principais potências e a periferia do capitalismo entraram num período de tensão e fragilidade. Paralelamente, avançavam as experiências "socialistas". Urgia conter uma possível mudança de ânimo na classe trabalhadora ocidental e manter, a qualquer custo, o pacto entre capital e trabalho nas economias de mercado, mesmo que a situação exigisse intervenções estatais deliberadas e que, no limite, se banalizasse a democracia. Assim, segundo Dias (1999:109): 
Paralelamente à experiência socialista, o Capitalismo viveu sua mais importante crise: a dos anos 30. Crise orgânica do Capital, ela viabilizou/tornou necessário um conjunto de medidas de contratendência que tratou de conduzir/reconduzir as classes trabalhadoras ao leito econômico-corporativo; implicou, ao mesmo tempo, na crise das formas estatais capitalistas, cristalizou-se na constituição de um bloco social que negava a forma clássica da sociabilidade capitalista e fez com que, no seu próprio campo, suas regras básicas de cidadania, de legalidade e legitimidade, fossem colocadas em dúvida (ver o nazismo, o fascismo, e outras formas ditatoriais). O capitalismo utilizou sem nenhum pudor ou constrangimento o nazismo e o fascismo como formas legítimas de imposição do seu projeto, de sua racionalidade. O fórceps fascista fez o parto do capitalismo fordista nas velhas economias européias. Embora isso possa chocar às belas almas, tanto o fascismo quanto a social-democracia foram vitais para a reconstrução do capitalismo.

Passado o período de auge do nazi-fascismo europeu e terminada a Segunda Grande Guerra (1939-1945), os EUA consolidaram-se como a primeira entre as potências imperialistas capitalistas envolvidas no conflito, entre outros motivos porque, em parte, o seu território não foi palco de invasão e destruição, tal como o território europeu. E também porque o impulso mais extraordinário até então alçado pela economia estadunidense foi dado exatamente nesta fase, via industrialização bélica. A acumulação de capital retomou novamente suas bases e acelerou sua expansão mundial, abrindo caminho a uma nova institucionalização, em que, de um lado, os EUA emergem como a potência capitalista por excelência na liderança da expansão da economia de mercado, frente a, de outro, a União das Repúblicas Socialistas Soviéticas (URSS), como a primeira grande potência socialista. Segundo Dias (1999:110):

Para impedir que a chamada experiência socialista conseguisse ampliar sua esfera de influência era necessário antecipar-se a ela. Os Estados Unidos acabaram por reconstruir os países capitalistas derrotados através do Plano Marshall, com capitais a fundo perdido, permitindo aos ex-inimigos - agora aliados - subtrair-se a qualquer possibilidade de serem submetidos por forças sociais comandadas pelos comunistas, ex-aliados, agora inimigos. Face à alternativa russa, fortíssima no imaginário dos trabalhadores, os capitalistas de todo o mundo uniram-se. De adversários da véspera à aliados do momento: tudo valia contra o espectro vermelho. Não foi o bastante. Tudo isto concomitantemente ao desenvolvimento do taylor-fordismo.

No âmbito nacional das potências capitalistas, abriu-se mão da exploração até então extraordinária do trabalho, afrouxando-se, por um período, os laços industriais 
repressivos na busca de se construir uma perspectiva de participação política para as classes trabalhadoras. Surge nesse contexto uma necessária conexão entre a industrialização massificadora do taylorismo/fordismo e o Estado de Bem-Estar Social (Welfare State), este último baseado no equilíbrio entre, de um lado, certa garantia de direitos políticos e sociais mínimos aos trabalhadores e, de outro, uma política econômica de crescimento keynesiana, cuja origem remonta aos anos que se seguiram à crise de 1929.

Procurou-se, assim, conter a classe trabalhadora dentro dos limites do capitalismo, amenizando os impactos do socialismo soviético por meio de uma agenda em que se destacava a preocupação com o emprego e a geração de renda, o compromisso com os idosos, desempregados e inválidos para o trabalho, além da criação de mecanismos de seguridade social-como planos de saúde, habitacionais, etc. Evidentemente, os resultados dependeram da capacidade fiscal do Estado nas diferentes nações em que se objetivava seguir tais propostas. Mas, de um modo ou de outro, tais políticas levaram a um crescimento das indústrias de construção civil, de vestuário, de alimentos e mesmo de bens de consumo duráveis nas principais potências capitalistas, decorrendo impactos positivos sobre a geração de emprego e renda (Harvey 1992; Mattoso 1994; Pochmann 1998).

A expansão internacional do taylorismo/fordismo no pós-1945 desenvolveu-se sob diversas formas, adaptando-se às condições nacionais heterogêneas de cada país, segundo suas relações de classe e o desenvolvimento de suas forças produtivas. Segundo Harvey (1992:132):

Tudo isso se abrigava sob o guarda-chuva hegemônico do poder econômico e financeiro dos Estados Unidos, baseado no domínio militar. O acordo de Bretton Woods, de 1944, transformou o dólar na moeda reserva mundial e vinculou com firmeza o desenvolvimento econômico do mundo à política fiscal e monetária norte-americana. A América agia como banqueiro do mundo em troca de uma abertura dos mercados de capital e de mercadorias ao poder das grandes corporações. Sob essa proteção, o fordismo se disseminou desigualmente, à medida que cada Estado procurava seu próprio modo de administração das relações de trabalho, da política monetária e fiscal, das estratégias de bem-estar e de investimento público, limitados internamente apenas pela situação das relações de classe e, externamente, somente pela posição hierárquica na economia mundial e pela taxa de câmbio fixada com base no dólar. Assim, a expansão internacional do fordismo ocorreu numa conjuntura particular de regulamentação político-econômica mundial e uma configuração geopolítica em que os Estados Unidos dominavam por meio de um sistema bem distinto de alianças militares e relações de poder. 
Nos países de capitalismo dependente, como na América Latina, a classe trabalhadora logrou um patamar mínimo de direitos, inclusive no que tange à regulamentação da estrutura e organização sindical. Na maioria dos casos, contudo, tais direitos foram outorgados pelo Estado, como parte da execução de um projeto político mais amplo, denominado "desenvolvimentista", mediante o qual uma fração das classes dominantes locais, inclinadas à industrialização (inclusive, em casos como o Brasil, contando com o apoio das Forças Armadas), buscou integrar tais países à economia mundial, visando superar: no plano externo, a dependência imposta pela divisão internacional do trabalho (que limitava estes países a meros exportadores de produtos primários); no plano interno, o arraigado conservadorismo das oligarquias agrárias (Martins 2011).

Nesse sentido é que se explica a busca por muitos países latino-americanos, durante a chamada "Guerra Fria", de lograr uma estrutura coerente com os objetivos de desenvolvimento social, econômico, político e cultural seguidos pelos países capitalistas, na liderança dos quais figurava os EUA. Nas palavras de Gramsci (1991:388):

A americanização exige um determinado ambiente, uma determinada estrutura social (ou vontade decidida de criá-la) e um determinado tipo de Estado. O Estado é o Estado liberal, não no sentido do liberalismo alfandegário ou da efetiva liberdade política, mas no sentido mais fundamental da livre iniciativa e do individualismo econômico que alcança através de meios próprios, como "sociedade civil", através do próprio desenvolvimento histórico, o regime da concentração industrial e do monopólio.

Atuando no limite das restrições que a acumulação de capital lhe impunha, o chamado Estado de Bem-Estar Social em nenhum momento proporcionou uma transformação revolucionária das condições de vida da classe trabalhadora. Bastou o advento de um novo ciclo de crise do capital na década de 1970 para que todos os compromissos estabelecidos até então fossem, novamente, abandonados.

\section{CONSIDERAÇÕES FINAIS}

Partindo da análise de Gramsci em "Americanismo e fordismo", é possível verificar que o taylorismo/fordismo, para além de uma metodologia de organização dos processos produtivos e de gestão da força de trabalho, apresentou-se como uma proposta de formação social de um novo tipo de trabalhador e de cidadão, adaptado ao consumo de massa. Um trabalhador cuja formação não mais seria forjada nas estruturas tradicionais 
dos ofícios, em que saberes-fazeres tácitos, historicamente acumulados pela classe trabalhadora, eram resguardados e transmitidos entre gerações.

As organizações como os sindicatos de ofícios foram dissipadas, emergindo em seu lugar um sindicalismo de massa, junto à expansão da industrialização de massa e do Estado de Bem-Estar no pós-1945. Um modelo de sindicalismo de ações oscilatórias, ora atuando como negociador com o grande capital e apoiando políticas reformistas junto ao Estado, ora mobilizando a classe trabalhadora, como em fins de 1960 nos países capitalistas centrais e nas décadas de 1970 e 1980 nas regiões periféricas tardiamente industrializadas (vide o caso de países da América Latina). De fato, muitas greves desse último período foram deflagradas pelos contingentes de trabalhadores semi-qualificados que se concentravam nas linhas de série das plantas fordistas verticalizadas, o que nos dá uma mostra de quão complexa e heterogênea foi a evolução desse sistema ao longo dos anos e as reações que provocou na classe trabalhadora.

Uma vez que a expansão dessa experiência para além da fábrica resultou na formação de uma nova classe trabalhadora e de uma nova forma de cidadania, ainda mais restrita aos limites da acumulação capitalista—ou seja, à reprodução salarial, à industrialização e ao consumo de massa-, a luta travada entre trabalho e capital sob a difusão do taylorismo/fordismo e do Estado de Bem-Estar Social, ocupando a maior parte do século $\mathrm{XX}$, revestiu-se de grande importância para a história.

Se por um lado, é consensual admitir-se que o máximo aproveitamento das instalações produtivas, com sucessivas inovações no plano organizacional (desde a hierarquia de cargos e salários até as atividades desempenhadas em cada posto de trabalho), é algo tão antigo quanto o próprio desenvolvimento do capitalismo de base industrial, por outro lado, se tomássemos aqui, por referência, uma análise do chamado Sistema Toyota de Produção, sucessor do taylorismo/fordismo após a crise dos anos 1970, seria notável o quanto, em muitos pontos, ambos encerram elementos de continuidade. Aliás, justamente quanto às formas de envolvimento ideológico buscando comprometer o operariado com os objetivos gerenciais-ou, de modo mais amplo, o trabalho com o capital.

A busca de ofuscar aos sujeitos envolvidos-gerência e operariado - as contradições do assalariamento e da divisão técnica e social do trabalho, é um dos feitos pioneiros do taylorismo/fordismo e que até a atualidade mantém-se como pedra angular da administração capitalista. A imposição de funções e postos entre os sujeitos no ambiente de trabalho, ora mais, ora menos hierarquizados ou rígidos, é uma necessidade básica da exploração do trabalho como mercadoria no capitalismo. Afinal, mais do que a simples eficiência na extração 
de mais-valia, é necessário que os trabalhadores projetem em suas relações cotidianas a forma relacional assumida pelos produtos do seu trabalho no âmbito do mercado. Projeção esta que deve obscurecer o quadro de exploração no qual contracenam.

Se Henry Ford, como um dos criadores da indústria de massa no início do século $\mathrm{XX}$, persuadiu seus trabalhadores propondo tornar-lhes, supostamente, potenciais consumidores dos seus próprios produtos, Taiichi Ohno, pai do Sistema Toyota de Produção, buscou persuadi-los propondo-lhes, também supostamente, uma participação nos negócios, devido à responsabilidade que lhes é atribuída nas empresas em que trabalham. Todavia, a ideologia, tão cara ao toyotismo, de que não somente o êxito, mas também o fracasso das operações deva ser assumido por todos, não é algo que se possa atribuir aos elementos tradicionais da cultura nipônica. Há, como apontou Gramsci, forte conexão entre o puritanismo e o comprometimento ideológico entre trabalho e capital nos EUA, berço cultural do taylorismo/fordismo.

Ainda que se trate aqui de tipos ideais, eles expressam como já havia, desde Taylor e Ford, a necessidade de articulação entre os métodos de gestão da força de trabalho e os elementos socioculturais de individualização e mercantilização na conduta dos trabalhadores. Como afirmamos em outro texto, “'vestir a camisa da empresa' foi tão comum em Detroit até meados do século XX, como no ABC paulista, a partir da década de 1950" (Pinto 2011:107). Ademais, tal como a difusão do toyotismo e do Estado Mínimo Neoliberal frente à crise dos anos 1970, a articulação entre o taylorismo/fordismo e o Estado de Bem-Estar Social também constituiu um movimento de reestruturação do capital diante de uma crise, que, àquela época, exigiu da classe dominante e de seus intelectuais orgânicos não apenas enfrentar a crônica e tendencial queda da taxa de lucro, mas o emergir de propostas concretas de superação desse modo de produção e de sociabilidade em outros países.

\section{REFERÊNCIAS}

Braverman, Harry. 1987. Trabalho e capital monopolista: a degradação do trabalho no século $X X$. Rio de Janeiro: LTC.

Dias, Edmundo Fernandes. 1999. A liberdade (im)possível na ordem do capital:reestruturação produtiva e passivização. Campinas, SP: IFCH-Unicamp (Textos Didáticos, n. 29).

Fleury, Afonso y Nilton Vargas. 1983. “Aspectos conceituais.” Pp. 17-37 en Organização do trabalho:uma abordagem interdisciplinar - sete estudos sobre a realidade brasileira, editado por A. Fleury y N. Vargas. São Paulo: Atlas. 
Ford, Henry. 1995. "Minha vida e minha obra." Pp. 107-59 en Henry Ford: por ele mesmo, editado por H. Ford. Sumaré, SP: Martin Claret.

Gramsci, Antonio. 1991. “Americanismo e fordismo.” Pp. 375-413 en Maquiavel, a política e o Estado moderno, editado por A. Gramsci. Rio de Janeiro: Civilização Brasileira.

-----. s/f. d. Quaderni del carcere. Roma: Edizione critica dell'Istituto Gramsci a cura di Valentino Gerratana. Edizione elettronica a cura dell'International Gramsci Society

Harvey, David. 1992. A condição pós-moderna. São Paulo: Loyola.

Lukács, György. 2004. Ontología del ser social:el trabajo. Buenos Aires: Herramienta.

Martins, Carlos Eduardo. 2011. "Dependência e desenvolvimento no moderno sistema mundial.” Pp. 213-74 en Globalização, dependência e neoliberalismo na América Latina, editado por C. E. Martins. São Paulo: Boitempo.

Marx, Karl. 1996. O capital: crítica da economia política. São Paulo: Nova Cultural. V. 1. T. 1.

Marx, Karl y Friedrich Engels. 2007. O manifesto comunista. São Paulo: Boitempo.

-----. 2009. A ideologia alemã:crítica da mais recente filosofia alemã em seus representantes Feuerbach, B. Bauer e Stirner, e do socialismo alemão em seus diferentes profetas (1845-1846). São Paulo: Boitempo.

Mattoso, Jorge. 1994. "O novo e inseguro mundo do trabalho nos países avançados." Pp. 52162 en $O$ mundo do trabalho:crise e mudança no final do século, editado por C. Oliveira et al. São Paulo: Página Aberta-Scritta.

Pinto, Geraldo Augusto. 2010. A organização do trabalho no século 20: taylorismo, fordismo e toyotismo. São Paulo: Expressão Popular.

-----. 2011. A máquina automotiva em suas partes: um estudo das estratégias do capital na indústria de autopeças. São Paulo: Boitempo.

Pochmann, Márcio. 1998. "Desemprego e políticas de emprego: tendências internacionais e o Brasil.” Pp. 219-33 en Economia \& Trabalho: textos básicos, editado por M. A. Oliveira. Campinas, SP: CESIT-IE-Ed. da UNICAMP.

Sennett, Richard. 2009. O artífice. Rio de Janeiro: Record. 
Silva, Benedicto. 1974. Taylor e Fayol. Rio de Janeiro: Ed. da Fundação Getúlio Vargas.

Souza, Ângela Tude de. 1992. Americanismo e fordismo em Gramsci. Campinas, SP: IFCHUnicamp (Textos Didáticos, n. 5).

Taylor, Frederick Winslow. 1970. Princípios de administração científica. São Paulo: Atlas. 